\section{Asthma prevalence and the relationship between level of knowledge and quality of life among asthmatic schoolchildren in Malaysia}

Jenny L. Dinglasan, RN, BSc, Li Y. Tang, RN, PhD, Mei C. Chong, RN, PhD, Abdulaziz M. Al Raimi, RN, PhD.

\section{ABSTRACT}

Objectives: To examine asthma prevalence and the relationship between the level of knowledge and quality of life (QoL) among asthmatic secondary school children aged 13-14 years old in Malaysia.

Methods: A cross-sectional design was employed. Data was collected through a self-administered questionnaire containing demographic characteristics, asthma symptoms, knowledge on asthma, and QoL.

Results: Data from 2891 asthmatic schoolchildren aged 13-14 years old from secondary schools in Petaling Jaya, Malaysia, were analyzed. According to the International Study of Asthma and Allergies in Childhood (ISAAC) scoring for asthma prevalence, the number of children who exhibited signs and symptoms of asthma was 9\% $(n=260)$. The mean score for total knowledge indicated a low knowledge level $(82.7 \%)$. No significant relationship was found between knowledge level and QoL. Only the race factor was associated with asthma knowledge.

Conclusion: This study has provided valuable information on asthma prevalence among Malaysian adolescents and their knowledge on asthma condition. Further research should explore the correlation factors of asthma knowledge and QoL.

Keywords: asthma, knowledge, quality of life, school health

Saudi Med J 2022; Vol. 43 (1): 113-116 doi: 10.15537/smj.2022.43.1.20210211

A thma is a syndrome characterized by intermittent attacks, breathlessness, wheezing, and cough. This condition often occurs during childhood and imposes a high lifetime burden on the individual, the caregiver, and the community. ${ }^{1}$ Asthma influences the lives of children in terms of physical, emotional, social aspects, and harm their families and society. ${ }^{2}$

Global Initiative for Asthma stated that asthma is one of the chronic respiratory diseases affecting 1-18\% of people from different countries. ${ }^{3}$ In Malaysia, asthma affects children and has high prevalence in urban areas. The estimated asthma prevalence in Malaysia had increased from $6.4-9.4 \%$ in children aged 6-7 years old and from $9-13 \%$ in children aged $13-14$ years old. ${ }^{4}$

Insufficient knowledge on asthma may affect quality of life (QoL), specifically the behavior and emotion of schoolchildren who are likely to develop a low self-esteem that will negatively influence their peer interaction. Hence, knowledge assessment is important in improving coping mechanisms for childhood asthma. ${ }^{5}$ Disease knowledge for an asthmatic child is crucial when settting positive attitudes toward asthma treatment, recognize symptoms, respond appropriately for effective disease management, asthma control, and good QoL. ${ }^{6}$

To identify the factors that contribute to the increasing prevalence of asthma, this study examines asthma prevalence and the relationship between knowledge level and QoL among asthmatic schoolchildren aged between 13-14 years old from secondary schools in Petaling Jaya, Malaysia.

Methods. This study used a cross-sectional design. Data was collected between March 2015-2016 through a self-administered questionnaire that examined asthma prevalence and the relationship between knowledge level and QoL among asthmatic schoolchildren aged between 13-14 years old from secondary schools in Petaling Jaya, Malaysia.

Petaling Jaya, Malaysia was selected as the study site, comprising of 29 secondary schools. The schools were clustered into 4, and 2 schools were selected from each cluster. Universal sampling was used to identify the study population, and purposeful random sampling was applied to determine the sample size. Among the 2891 schoolchildren, 260 were asthma patients aged 13-14 years. However, 46 schoolchildren did not participate in the second phase of the study (namely, assessment of knowledge and QOL), because they were afraid. Therefore, the sample size was 214 respondents. Study outcomes were assessed based on symptom description (International Study of Asthma and Allergies in Childhood [ISAAC]) rather than disease diagnosis. ${ }^{7}$ Students with known chronic heart diseases were excluded to minimize the influence of other diseases with symptoms similar to asthma. A consent form was

Disclosure. This study was funded by a grant under the Institute of Research Management and Services (IPPP), University Malaya, Kuala Lumpur, Malaysia. 
given to the schoolchildren prior to the distribution of the questionnaires.

Data was collected using a self-administered questionnaire comprising 4 sections: demographic data questionnaire, ISAAC, knowledge of asthma questionnaire, and Pediatric Asthma Quality of Life Questionnaire (PAQLQ). ${ }^{8,9}$

The first questionnaire on demographic data consists of the participants' gender, age, race, disease status, and medical compliance, and asked where they would go for treatment and what medications they were using.

The second questionnaire (ISAAC) determined asthma prevalence and consists of 3 written questionnaires and 3 video questionnaires that assess the lifetime prevalence of asthma symptoms. A total of 2891 schoolchildren were asked to first complete the written questionnaires, followed by the video questionnaires. The screening process included determining the combination of wheezing and the presence of other asthma symptoms within the past 12 months.

The third questionnaire assesses asthma knowledge. The researcher developed and validated this tool based on previous studies. This form consists of 33 items that measure knowledge level and was adapted from the hospital asthma team. The items were closed-ended questions and can be answered through a Likert scale of "yes," "no," and "don't know." The questionnaire included items on basic knowledge, signs and symptoms, triggers, and treatment/management.

The last questionnaire (PAQLQ) adapted from the work of Elizabeth Juniper and is an effective and validated tool to assess health-related quality of life in children and adolescents with asthma. ${ }^{10}$ This form consists of 23 items across 3 main domains (symptoms, activity limitation, and emotional function) and is rated on a 7 -point scale.

The researcher spent approximately 2 days to complete the survey in each secondary school. After collecting the questionnaires, the researcher identified the specific target group using ISAAC, namely, schoolchildren with asthma. Schoolchildren with chronic illness were excluded. Asthma knowledge and QoL were assessed using the asthma knowledge tool and PAQLQ. ${ }^{9}$

Permission was granted by the Ministry of Education, the Ministry of Health, and the respective schools and principals. This study was registered under the Medical Research Committee, University Malaya, Kuala Lumpur, Malaysia, Medical Centre, MRECID. NO: 2016112-4501.

Statistical analysis. Descriptive and inferential statistics were used to summarize the demography of the students and their knowledge level. Mean and standard deviation were calculated from the quantitative data. Chi-squared test was applied to determine the associations between categories. All statistical analyses were conducted using Statistical Package for the Social Sciences for Windows, version 22.0 (IBM Corp., Armonk, NY, USA). A $p$-value of $<0.05$ was considered significant.

Results. Table 1 shows the lifetime prevalence of asthma symptoms according to the ISAAC questionnaire. Wheeze (ever) asthma symptom is an effective strategy to confirm the diagnosis of asthma and thus was used in this study. ${ }^{11}$ On the basis of the ISAAC scoring, the asthma prevalence was 9\% ( $n=260)$.

Table 2 displays the Chi-square test results for sociodemographic factors affecting knowledge. Except race, all factors show no statistically significant difference $(p \leq 0.05)$ in asthma knowledge level. Only race has a high correlation with knowledge level with a $p=0.02(p<0.05)$.

Table 3 shows the results of Pearson's correlation analysis on the relationship between knowledge and QoL variables. No significant relationship was found between knowledge level and QoL with a $p=0.69$ $(p>0.05)$.

Discussion. The respondents were 214 asthmatic children aged 13-14 years old from 6 secondary schools, Petaling Jaya, Malaysia. The majority of the participants $(118,55 \%)$ were females, who are proven to be more likely to be diagnosed with asthma than males. A similar study by Al-Kubaisy et al, ${ }^{12}$ showed a substantial association between gender and asthma in Iraq. Another report from Naeem et $\mathrm{al},{ }^{13}$ who found that boys are more exposed to asthma than girls, though the pattern is reversed after puberty.

This research also found that race is the only demographic factor associated with knowledge level. This finding is similar to those from a study in Malaysia by Roslan et $\mathrm{al},{ }^{14}$ who showed that race is associated with asthma, especially in Malays.

Table 1 - Prevalence of asthma symptoms by the International Study of Asthma and Allergies in Childhood (ISAAC) written questionnaire ( $\mathrm{N}=2891)$.

\begin{tabular}{lcc}
\hline Asthma symptoms & Yes & No \\
& $\mathbf{n}(\%)$ & \\
\hline Wheeze (ever) & $260(8.99)$ & $2631(91.01)$ \\
Wheeze (12-month prevalence) & $122(4.22)$ & $2769(95.78)$ \\
Severe asthma (12-month prevalence) & $39(1.35)$ & $2852(98.65)$ \\
\hline
\end{tabular}


Table 2 - Relationship between knowledge level and demographic factors among asthmatic schoolchildren $(\mathrm{N}=214)$.

\begin{tabular}{|c|c|c|c|c|c|}
\hline \multirow[t]{3}{*}{ Variables } & \multirow[t]{3}{*}{$\mathrm{n}$} & \multicolumn{3}{|c|}{ Knowledge } & \multirow[t]{3}{*}{$P$-value } \\
\hline & & Low (<11 marks) & Moderate (11-22 marks) & High (>22 marks) & \\
\hline & & \multicolumn{3}{|c|}{ n (\%) } & \\
\hline \multicolumn{6}{|l|}{ Gender } \\
\hline Male & 96 & $77(80.2)$ & $18(18.8)$ & $1(1.0)$ & \multirow{2}{*}{0.32} \\
\hline Female & 118 & $100(84.7)$ & $14(11.9)$ & $4(3.4)$ & \\
\hline \multicolumn{6}{|l|}{ Age } \\
\hline 13 & 93 & $73(78.5)$ & $16(17.2)$ & $4(4.3)$ & \multirow{2}{*}{0.28} \\
\hline 14 & 121 & $104(86.0)$ & $16(13.2)$ & $1(0.8)$ & \\
\hline \multicolumn{6}{|l|}{ Race } \\
\hline Malay & 149 & $135(90.6)$ & $11(7.4)$ & $3(2.0)$ & \multirow{4}{*}{$<0.001$} \\
\hline Indian & 44 & $27(61.4)$ & $15(34.1)$ & $2(4.5)$ & \\
\hline Chinese & 20 & $14(70.0)$ & $6(30.0)$ & $0(0)$ & \\
\hline Others & 1 & $1(100)$ & $0(0.0)$ & $0(0)$ & \\
\hline \multicolumn{6}{|c|}{ Are there other family members of yours who have asthma? } \\
\hline No & 158 & $133(84.2)$ & $21(13.3)$ & $4(2.5)$ & \multirow{2}{*}{0.05} \\
\hline Yes & 56 & $44(78.6)$ & $11(19.6)$ & $1(1.8)$ & \\
\hline \multicolumn{6}{|c|}{ What types of medication do you use to treat asthma? } \\
\hline Inhaler & 101 & $86(85.1)$ & $13(12.9)$ & $2(2.0)$ & \multirow{3}{*}{0.19} \\
\hline Oral medications & 67 & $58(86.6)$ & $7(10.4)$ & $2(3.0)$ & \\
\hline Not applicable & 46 & $33(71.7)$ & $12(26.1)$ & $1(2.2)$ & \\
\hline
\end{tabular}

Table 3 - Relationship between asthma knowledge and overall quality of life (N=214).

\begin{tabular}{lcccc}
\hline Asthma knowledge levels & $\mathbf{n}$ & Minimum or no impairment $(>6)$ & $\begin{array}{c}\text { Moderate impairment (3-5.9) } \\
\mathbf{n}(\%)\end{array}$ & Severe impairment $(<3)$ \\
\hline Low (<11 marks) & 177 & $108(61.0)$ & $67(37.9)$ & $2(1.1)$ \\
Moderate (11-22 marks) & 32 & $23(71.9)$ & $9(28.1)$ & $0(0.0)$ \\
High (>22 marks) & 5 & $4(71.9)$ & $1(20.0)$ & $0(0.0)$ \\
\hline
\end{tabular}

The studied factors are asthma prevalence, knowledge level, QoL, and demographics. Current findings are similar to those from previous studies in different contexts. One of the highly prevalent asthma symptoms among children is wheeze (ever), followed by wheeze and severe asthma (12-month prevalence). Children aged 13-14 years old had wheeze (ever) as the main asthma symptom as revealed by the ISAAC questionnaire, a tool to identify asthmatic patients.

Most of the respondents had a low asthma knowledge level. Thus, educating them through their parents and school is crucial. Quality of life was moderate among these children. Hence, a low knowledge level may lead to a moderate QoL among the affected children. Fontan et al, ${ }^{15}$ reported that children with asthma have an impaired QoL. Quality of life has 3 main domains, namely, activity limitation, symptoms, and emotional function.
No statistically significant relationship was found between knowledge level and QoL among asthmatic schoolchildren. One possible reason is that the crosssectional data and sample size were not defined according to the power of statistical alpha and beta. In addition, the available data is not sufficiently valid to assess the actual relationships between asthma knowledge and QoL. When children are made aware of the importance of asthma knowledge, their QoL can improve. ${ }^{16}$

Study limitations. Research involving asthmatic schoolchildren can be challenging, especially with adolescents (13-14 years old). First, the sample size was not defined according to the power of statistical alpha and beta. Second, ISAAC was used for outcome assessment rather than medical diagnosis. Given that the adolescent participants are in the age of personality development where they start to build their own identity, this phenomenon may lead to conflicts in expressing their feelings toward their disease. 
In conclusion, results show a low knowledge level about asthma and no relationship between QoL and knowledge level. Thus, healthcare organizations must identify asthmatic schoolchildren and guide them to manage their condition by recognizing its symptoms.

Further research should explore the correlation factors of asthma knowledge and QoL, new strategies for improvement, and the possibility of reducing or preventing asthma prevalence.

Acknowledgment. The authors gratefully acknowledge to all the participants, research investigators, and the staff, for their cooperation and contribution. We also would like to thank Nellie C. Li and KG Support Limited (www.kgsupport.com) for English language editing.

Received 5th September 2021. Accepted 28th October 2021.

From the Department of Nursing (Dinglasan, Tang, Chong, Al Raimi), Faculty of Medicine, University Malaya, Kuala Lumpur, Malaysia, and from the Department of Nursing (Al Raimi), Seiyun Community College, Seiyun, Yemen.

Address correspondence and reprints request to: Dr. Li Y. Tang, senior lecturer, Department of Nursing Science, Faculty of Medicine, University of Malaya, Kuala Lumpur, Malaysia. E-mail: lytang@ummc.edu.my

ORCID ID: https://orcid.org/0000-0001-9460-4208

\section{References}

1. Ferrante G, La Grutta S. The burden of pediatric asthma. Front Pediatr 2018; 6: 186.

2. Montella S, Baraldi E, Cazzato S, Aralla R, Berardi M, Brunetti LM, et al. Severe asthma features in children: a case-control online survey. Ital J Pediatr 2016; 42: 9.

3. Global Initiative for Asthma. 2021 GINA report: Global strategy for asthma management and prevention. [Updated 2018; 2021 Dec 8]. Available from: https://ginasthma.org/

4. Yadav R, Yadav H, Leong TK. Factors influencing acute exacerbation of bronchial asthma among children in Malaysia. Int. J of Child Health and Nutr. 2014; 3: 17-26.

5. Knibb RC, Alviani C, Garriga-Baraut T, Mortz CG, VazquezOrtiz M, Angier E, et al. The effectiveness of interventions to improve self-management for adolescents and young adults with allergic conditions: a systematic review. Allergy 2020; 75 : 1881-1898.
6. Kuti BP, Omole KO, Kuti DK. Factors associated with childhood asthma control in a resource-poor center. J Family Med Prim Care 2017; 6: 222-230.

7. Rutter CE, Silverwood RJ, Asher MI, Ellwood P, Pearce N, Garcia-Marcos L, et al. Comparison of individual-level and population-level risk factors for rhinoconjunctivitis, asthma, and eczema in the International Study of Asthma and Allergies in Childhood (ISAAC) phase three. World Allergy Organ J 2020; 13: 100123.

8. Carr TF, Beamer PI, Rothers J, Stern DA, Gerald LB, Rosales $\mathrm{CB}$, et al. Prevalence of asthma in school children on the Arizona-Sonora Border. J Allergy Clin Immunol Pract 2017; 5: 114-120.

9. Roncada C, Mattiello R, Pitrez PM, Sarria EE. Specific instruments to assess quality of life in children and adolescents with asthma. J Pediatr (Rio J) 2013; 89: 217-225.

10. Melgarejo González-Conde V, Pérez-Fernández V, RuizEsteban C, Valverde-Molina J. Impact of self-efficacy on the quality of life of children with asthma and their caregivers. Arch Bronconeumol (Engl Ed) 2019; 55: 189-194.

11. Arianto L, Hallas H, Stokholm J, Bønnelykke K, Bisgaard H, Chawes BL. Multiple breath washout for diagnosing asthma and persistent wheeze in young children. Ann Am Thorac Soc 2019; 16: 599-605.

12. Al-Kubaisy W, Ali SH, Al-Thamiri D. Pediatric asthma and its relation to sociodemographic factors in Baghdad. Asian Journal of Environment-Behaviour Studies 2017; 2: 75-84.

13. Naeem A, Silveyra P. Sex differences in paediatric and adult asthma. Eur Med J (Chelmsf) 2019; 4: 27-35.

14. Roslan MS, Johari M, Mubing N, Fadzilah H. Sociodemographic profile of childhood asthma among children in SelangorMalaysia. Pediatric Research 2011; 70: 557-557.

15. Fontan FCS, Duwe SW, Santos KD, Silva JD. Quality of life evaluation and associated factors in asthmatic children and adolescents attended in a specialized outpatient clinic. Rev Paul Pediatr 2020; 38: e2018172.

16. Sukri N, Ramdzan SN, Liew SM, Salim H, Khoo EM. Perceptions of childhood asthma and its control among Malays in Malaysia: a qualitative study. NPJ Prim Care Respir Med 2020; 30: 26. 